\title{
Benefits of High-Intensity Exercise Training to Patients with Chronic Obstructive Pulmonary Disease: A Controlled Study
}

\author{
Tobias Boeselt ${ }^{\mathrm{a}}$ Christoph Nell ${ }^{\mathrm{a}}$ Lea Lütteken ${ }^{\mathrm{a}}$ Katharina Kehr ${ }^{\mathrm{a}}$ \\ Janine Koepke $^{\mathrm{a}}$ Sandra Apelt ${ }^{\mathrm{b}}$ Martina Veith ${ }^{\mathrm{a}}$ Björn Beutel ${ }^{\mathrm{a}}$ \\ Marc Spielmanns ${ }^{d,}$ e Timm Greulich ${ }^{a}$ Claus F. Vogelmeier ${ }^{a}$ Klaus Kenn ${ }^{c}$ \\ Sabina Janciauskiene ${ }^{f}$ Peter Alter $^{a} \quad$ A. Rembert Koczulla ${ }^{a}$ \\ ${ }^{a}$ Department of Medicine, Pulmonary and Critical Care Medicine, University Medical Center Giessen and \\ Marburg, Philipps-Universität Marburg, Member of the German Center for Lung Research (DZL), \\ ${ }^{b}$ Department of Physical Therapy, University Hospital of Giessen and Marburg, and ' Department of Pulmonology, \\ Schön Klinik Berchtesgadener Land, Philipps-Universität Marburg, Marburg, d Outpatient Pulmonary Rehabilitation, \\ St. Remigius Hospital Opladen, Leverkusen Opladen, ${ }^{\mathrm{e}}$ Medical School, Witten/Herdecke University, Witten, and \\ fDepartment of Pulmonology, Hannover Medical School, Member of the German Center for Lung Research (DZL), \\ Hannover, Germany
}

\section{Keywords}

Chronic obstructive pulmonary disease $\cdot$ Strength exercise · Training · High intensity - Quality of life · Six-minute walk test

\begin{abstract}
Background: Various exercise training programs are used for patients with chronic obstructive pulmonary disease (COPD) of different severity. Objectives: To investigate the impact of individualized high-intensity training on exercise capacity with COPD. Methods: A total of 49 patients agreed to participate. Of these, 31 were assigned to the training group and 18 served as controls. The training group exercised twice a week for 90 min with consecutively increasing loads. At the time of enrollment $\left(T_{0}\right)$, as well as after $3\left(T_{1}\right)$ and $6\left(T_{2}\right)$ months, a 6-min walk test (6-MWT) was performed and data on health-related quality of life, femoral muscle thickness, and various serum markers were obtained. Results: The
\end{abstract}

๑ 2017 S. Karger AG, Basel

E-Mail karger@karger.com www.karger.com/res training group improved in their 6-MWT results $\left(\mathrm{T}_{0}=407 \pm\right.$ $152 \mathrm{~m}$ vs. $\mathrm{T}_{1}=459 \pm 127 \mathrm{~m}, p=0.002$, vs. $\mathrm{T}_{2}=483.2 \pm 130.1$ $\mathrm{m}, p=0.004)$, in their cross-sectional area of the musculus rectus femoris $\left(T_{0}=6.2 \pm 1.2 \mathrm{~cm}^{2}\right.$ vs. $T_{1}=6.9 \pm 1.2 \mathrm{~cm}^{2}, p=$ 0.003 , vs. $7.5 \pm 1.6 \mathrm{~cm}^{2}, p=0.002$ ), and in their St. George's Respiratory Questionnaire (SGRQ) score $\left(\mathrm{T}_{0}=43.3 \pm 18.0 \mathrm{vs}\right.$. $\mathrm{T}_{1}=36.0 \pm 18.4, p=0.001$, vs. $\mathrm{T}_{2}=34.7 \pm 18.0, p=0.004$ ). Serum levels of myostatin, irisin, resistin, and a-Klotho did not change significantly within the training period. Of note, the exercise group showed an inverse relationship between serum levels of resistin and those of a-Klotho after 6 months $(r=-0.608, p=0.021)$. Conclusions: COPD patients undergoing an individualized, structured, high-intensity training program improved their exercise capacity, gained muscle mass, and improved their quality of life.

(c) 2017 S. Karger AG, Basel

Trial registration: DRKS00006842, retrospectively registered September 28,2016 . T.B. and C.N. contributed equally to this work.
Tobias Boeselt, PhD or Prof. A. Rembert Koczulla, MD

Department of Medicine, Pulmonary and Critical Care Medicine University Medical Center Giessen and Marburg, Philipps-Universität Marburg DE-35043 Marburg (Germany)

E-Mail tobias.boeselt@ uni-marburg.de or koczulla@med.uni-marburg.de 


\section{Introduction}

Chronic obstructive pulmonary disease (COPD) is a progressive airway disease and a common cause of morbidity and mortality. The prevalence of COPD increases with age and is associated with reduced physical activity [1]. COPD patients are at increased risk of entering a vicious circle of symptom progression causing reduced physical activity, social isolation, increased anxiety, and depression [2], as well as further inactivity, which is expected to lead to structural and biochemical muscular alterations associated with increased discomfort during exercise [3]. The most frequently observed pathologic features of skeletal muscles of COPD patients are myopathic changes due to pulmonary cachexia and/or steroid therapy [4].

During the last 2 decades, various well-designed, randomized, controlled clinical trials have shown that pulmonary rehabilitation is an effective nonpharmacological intervention for improving the health status in COPD patients [5], and it has become an established part of care for COPD patients. Various training programs have been shown to provide positive effects on patients' physical and mental well-being [6], as well as on muscle composition [7] and quality of life [8]. Several studies have demonstrated that exercise training-induced improvements are accompanied by a decrease in inflammatory markers, such as IL-8, and an increase in muscle activity parameters, such as peroxisome proliferator-activated receptor- $\gamma$ coactivator 1- $\alpha$ and irisin [9-11]. Finally, exercise training is a cost-effective intervention and reduces the number of hospitalizations [12].

In this context, different training modalities have been proposed to optimize exercise tolerance and to maximize training effects in patients with COPD. Nevertheless, it still remains unclear which exercise modalities are the most effective. Guidelines [13] recommend strength training 2-3 times a week and endurance training at moderate intensity 3-5 times a week; less is known about more intensive training concepts, including a quick escalation of exercise intensity.

We hypothesized that high-intensity training leads to an improvement of exercise capacity and reduced inflammatory activity. Therefore, we examined the effects of high-intensity exercise training of COPD patients on walking distance during the 6-min walk test (6-MWT) and on serum biomarker levels when compared to controls.

\section{Subjects and Methods}

\section{Study Outline}

Between January 2009 and December 2014, we invited 119 patients with mild to very severe COPD to participate in the study. Finally, 49 COPD patients without exacerbations for at least 4 weeks were enrolled in our prospective, nonrandomized interventional study conducted in the outpatient clinic of the University Hospital of Marburg. Thirty-one patients wished to be allocated to the exercise group, and each had an individualized outpatient strength training twice a week over a 3 -month period with a fast increase in load. A subgroup of 14 patients agreed to continue the assigned training program for an additional 3 months.

Eighteen patients refused to participate in the training group due to different causes and gave written consent to serve as controls. In order to fulfil the study protocol, a training participation of at least $80 \%$ was required. The primary endpoint of this study was a difference in 6-MWT distance from baseline to 3 months between the exercise and the control group. Every patient gave informed written consent to participate in the study. The study was approved by the Ethics Committee of the Philipps-Universität Marburg (Ethics Committee AZ 7/13, Marburg, Germany) and registered (DRKS00006842).

\section{Training Program}

The exercise group underwent an individualized physical strength outpatient training 2 times a week for $90 \mathrm{~min}$ at the Department of Physiotherapy of the University Hospital of Marburg. The group was led by a specially educated physiotherapist. The training program was split into two 3 -month exercise phases. The composition of the training was based on the guidelines of the American Association of Cardiovascular and Pulmonary Rehabilitation (ACCP/AACVPR) [14].

Each patient underwent a training schedule based on his/her exercise capacity, i.e., maximal force and endurance time in the different modalities (repetition method of Radlinger et al. [15]). In the first training session, a test of maximal force was repeated to adjust the training schedule at weeks 3,7 , and 11. Measurement of endurance capacity was performed on a bicycle ergometer: each patient started to cycle on an ergometer set at $25 \mathrm{~W}$. The exercise load was increased by $25 \mathrm{~W}$ every minute. At the same time, we asked the participants to estimate their grade of exertion and dyspnea (Borg scale, ranging from 0 to 10 ). Simultaneously, oxygen saturation was monitored. The test was stopped when a patient reached 20 on the Borg scale or the oxygen saturation decreased below $90 \%$. Disease-specific techniques (body positions and different breath and cough techniques, such as pursed-lip breathing) were communicated to the group.

There was a special focus on the following muscle groups: thigh muscles (especially musculus quadriceps femoris), lateral hip and trunk stabilizers, anterior shoulder muscles, rotator cuff muscles, different muscles of the upper extremities and dorsal trunk, and scapular stabilizers. The training equipment used was a leg press, leg squats, a cable pulldown, and a cable row. During the first 3 months, the intensity of the training changed from 35 to $75 \%$ of the maximal muscle strength of exercise. An overview of training strength, repetition, and series parameters is given in Table 1.

During the second session, the exercise intensity was kept constant but was switched towards muscle strength retention. The pa-
302

Respiration 2017;93:301-310

DOI: 10.1159/000464139
Boeselt et al. 
Fig. 1. Flowchart of patient recruitment, enrollment $\left(\mathrm{T}_{0}\right)$, and follow-up measurements $\left(T_{1}, T_{2}\right)$.

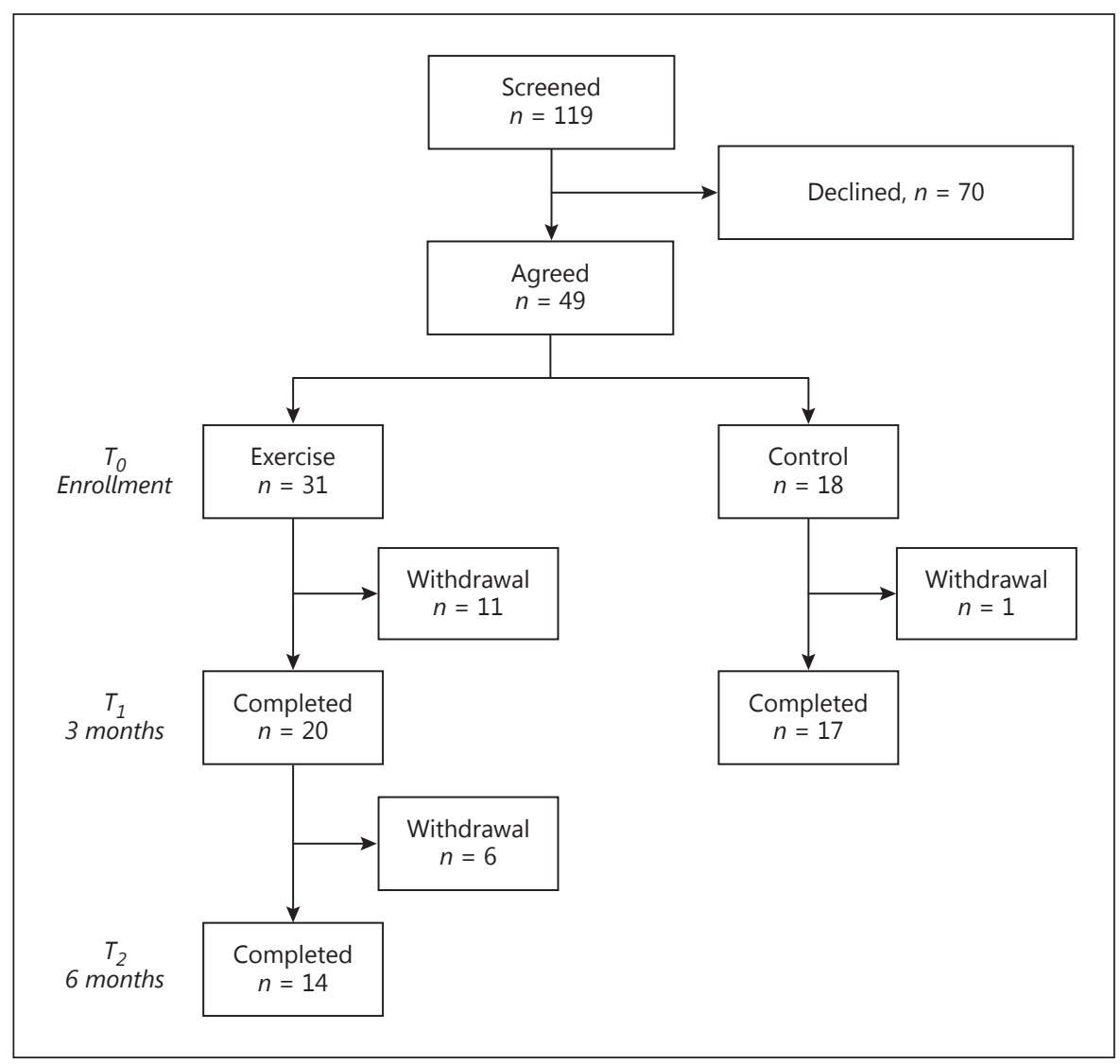

Table 1. Overview of the training schedule

\begin{tabular}{|c|c|c|c|c|c|c|c|c|c|c|c|c|}
\hline & \multicolumn{12}{|c|}{ Week } \\
\hline & 1 & 2 & 3 & 4 & 5 & 6 & 7 & 8 & 9 & 10 & 11 & 12 \\
\hline Intensity of maximal force, $\%$ & 35 & 40 & 40 & 45 & 60 & 65 & 65 & 65 & 70 & 75 & 75 & 75 \\
\hline Repetitions & 3 & 2 & 2 & 3 & 2 & 2 & 2 & 2 & 2 & 2 & 3 & $3-4$ \\
\hline Series & 20 & 20 & 20 & 20 & 20 & 15 & 15 & 15 & 15 & 15 & 15 & 15 \\
\hline
\end{tabular}

The intensity of the training changed during the first 3 months from 35 to $75 \%$ of the maximal muscle strength of exercise. The training was adjusted in weeks 3,7 , and 11 in the first session (bold type).

tients trained with $70 \%$ of their maximal muscle strength of exercise, each with 2 repetitions and 20 series. The training schedule was adjusted if a patient was under- or overchallenged.

No intervention was performed in the control group. These patients were observed for 3 months.

\section{Monitoring Training Benefits}

Patient assessment was performed before the start of the training $\left(\mathrm{T}_{0}\right)$, after 3 months $\left(\mathrm{T}_{1}\right)$, and, in a subgroup of 14 patients, after 6 months $\left(\mathrm{T}_{2}\right)$. Assessments included the 6-MWT [16] and an assessment of health-related quality of life by the St. George's Respiratory Questionnaire (SGRQ) [17]. Measurement of the cross-sectional area of the rectus femoris muscle was performed using ultrasonography as described by Seymour et al. [18]. While the patients were in a supine position, the transducer was placed perpendicular to the long axis of the thigh on its superior aspect, three-fifths of the distance from the anterior superior iliac spine to the superior patellar border. The area was calculated as an average of 3 consecutive measurements.

\section{Analysis of Serum Markers}

Serum concentrations of irisin and soluble a-Klotho were analyzed using commercially available ELISA kits (irisin: Phoenix Pharmaceuticals, Inc., Burlingame, CA, USA; detection range: 
Table 2. Baseline characteristics of the participants completing the study (per protocol)

\begin{tabular}{|c|c|c|c|c|}
\hline Measures and comorbidities & $\begin{array}{l}\text { All } \\
(n=37)\end{array}$ & $\begin{array}{l}\text { Control group } \\
(n=17)\end{array}$ & $\begin{array}{l}\text { Exercise group } \\
(n=20)\end{array}$ & $p$ value \\
\hline \multicolumn{5}{|l|}{ Baseline characteristics } \\
\hline Age, years & $65.73 \pm 8.3$ & $65.59 \pm 8.65$ & $65.85 \pm 8.21$ & ns \\
\hline Gender (male/female), $n$ & $26 / 11$ & $10 / 7$ & $16 / 4$ & ns \\
\hline BMI & $29.41 \pm 5.55$ & $29.69 \pm 6.0$ & $29.16 \pm 5.28$ & ns \\
\hline Current smokers, $n$ & 4 & 3 & 1 & ns \\
\hline \multicolumn{5}{|l|}{ Spirometry } \\
\hline \multicolumn{5}{|l|}{ COPD stage } \\
\hline I & 15 & 5 & 10 & ns \\
\hline II & 14 & 9 & 5 & ns \\
\hline III & 4 & 2 & 2 & ns \\
\hline IV & 4 & 1 & 3 & ns \\
\hline $\mathrm{FEV}_{1}, \%$ predicted & $67.66 \pm 24.10$ & $67.37 \pm 17.1$ & $67.91 \pm 29.23$ & ns \\
\hline $\mathrm{FEV}_{1} / \mathrm{FVC}, \%$ & $52.24 \pm 14.45$ & $54.22 \pm 12.83$ & $50.55 \pm 15.83$ & ns \\
\hline $\mathrm{R}_{\text {tot }}, \mathrm{kPa} \times \mathrm{s} / \mathrm{L}$ & $0.43 \pm 0.20$ & $0.40 \pm 0.09$ & $0.45 \pm 0.26$ & ns \\
\hline ITGV, \% predicted & $129.48 \pm 37.16$ & $126.22 \pm 22.20$ & $132.25 \pm 46.74$ & ns \\
\hline \multicolumn{5}{|c|}{ Symptoms and oxygen saturation during the 6-MWT } \\
\hline Borg scale, RPE & $2.17 \pm 1.38$ & $2.1 \pm 1.6$ & $2.4 \pm 1.2$ & ns \\
\hline $\mathrm{SaO}_{2}, \%$ & $95.71 \pm 1.58$ & $95.5 \pm 1.7$ & $96 \pm 1.4$ & ns \\
\hline \multicolumn{5}{|l|}{ COPD treatment, $n$} \\
\hline LAMA & 15 & 8 & 7 & ns \\
\hline ICS & 10 & 4 & 6 & ns \\
\hline $\mathrm{ICS}+\mathrm{LABA}$ & 14 & 8 & 6 & ns \\
\hline \multicolumn{5}{|l|}{ Comorbidities, $n$} \\
\hline Obesity & 14 & 8 & 6 & ns \\
\hline Arterial hypertension & 11 & 6 & 5 & ns \\
\hline Cardiac diseases & 5 & 3 & 2 & ns \\
\hline Diabetes mellitus type 2 & 3 & 1 & 2 & ns \\
\hline \multicolumn{5}{|l|}{ Comorbidity treatment } \\
\hline$\beta$-Blocker & 16 & $7(41 \%)$ & $9(45 \%)$ & ns \\
\hline ACE inhibitor/ARB & 17 & $8(47 \%)$ & $9(45 \%)$ & ns \\
\hline Diuretic agent & 14 & $6(35 \%)$ & $8(40 \%)$ & ns \\
\hline Calcium antagonist & 7 & $3(18 \%)$ & $4(20 \%)$ & ns \\
\hline Aldosterone antagonist & 5 & $2(12 \%)$ & $3(15 \%)$ & ns \\
\hline
\end{tabular}

Data are presented as the mean \pm SD unless specified otherwise. BMI, body mass index; COPD, chronic obstructive pulmonary disease; $\mathrm{FEV}_{1}$, forced expiratory volume in $1 \mathrm{~s} ; \mathrm{FVC}$, forced vital capacity; $\mathrm{R}_{\text {tot }}$, total airway resistance; ITGV, intrathoracic gas volume; 6-MWT, 6-min walk test; RPE, rating of perceived exertion (0-10); $\mathrm{SaO}_{2}$, oxygen saturation; LAMA, long-acting muscarinic antagonist; ICS, inhaled corticosteroids; LABA, longacting $\beta$-adrenoceptor agonist; $A R B$, angiotensin receptor blocker.

0.066-1,024 ng/mL, serum dilution 1:2; $\alpha$-Klotho: Immuno-Biological Laboratories Co., Phoenix, AZ, USA; detection range: 93.75-6,000 pg/mL, serum dilution 1:2). Myostatin (CDF-8) was quantified using precoated Quantikine ELISAs (R\&D Systems, Bio-Techne, Wiesbaden-Nordenstadt, Germany; detection range: $31.3-2,000 \mathrm{pg} / \mathrm{mL}$, serum dilution 1:4). Resistin was measured using Duo Set ELISA kits (R\&D Systems, Bio-Techne; detection range: $31.2-2,000 \mathrm{pg} / \mathrm{mL}$, serum dilution 1:20). All samples were measured in duplicate using a plate reader (Infinite ${ }^{\circledR}$ F200pro; Tecan, Männedorf, Switzerland) as described elsewhere [13].

\section{Statistics and Data Analysis}

Sample size calculation was performed using $G^{*}$ Power 3.1 and yielded a total sample size of 18 subjects considering 2 degrees of freedom with a power ( 1 - beta) of $95 \%$ and an alpha of $5 \%$ (primary endpoint). Based on the study protocol, all data were calcu- 
Fig. 2. a Improvement in exercise capacity (6-MWT). b Increase in the cross-sectional area of the musculus rectus femoris $(\mathrm{m}$. rect. femoris). c Significant improvement in SGRQ total score. 6-MWT, 6-min walk test; SGRQ, St. George's Respiratory Questionnaire.

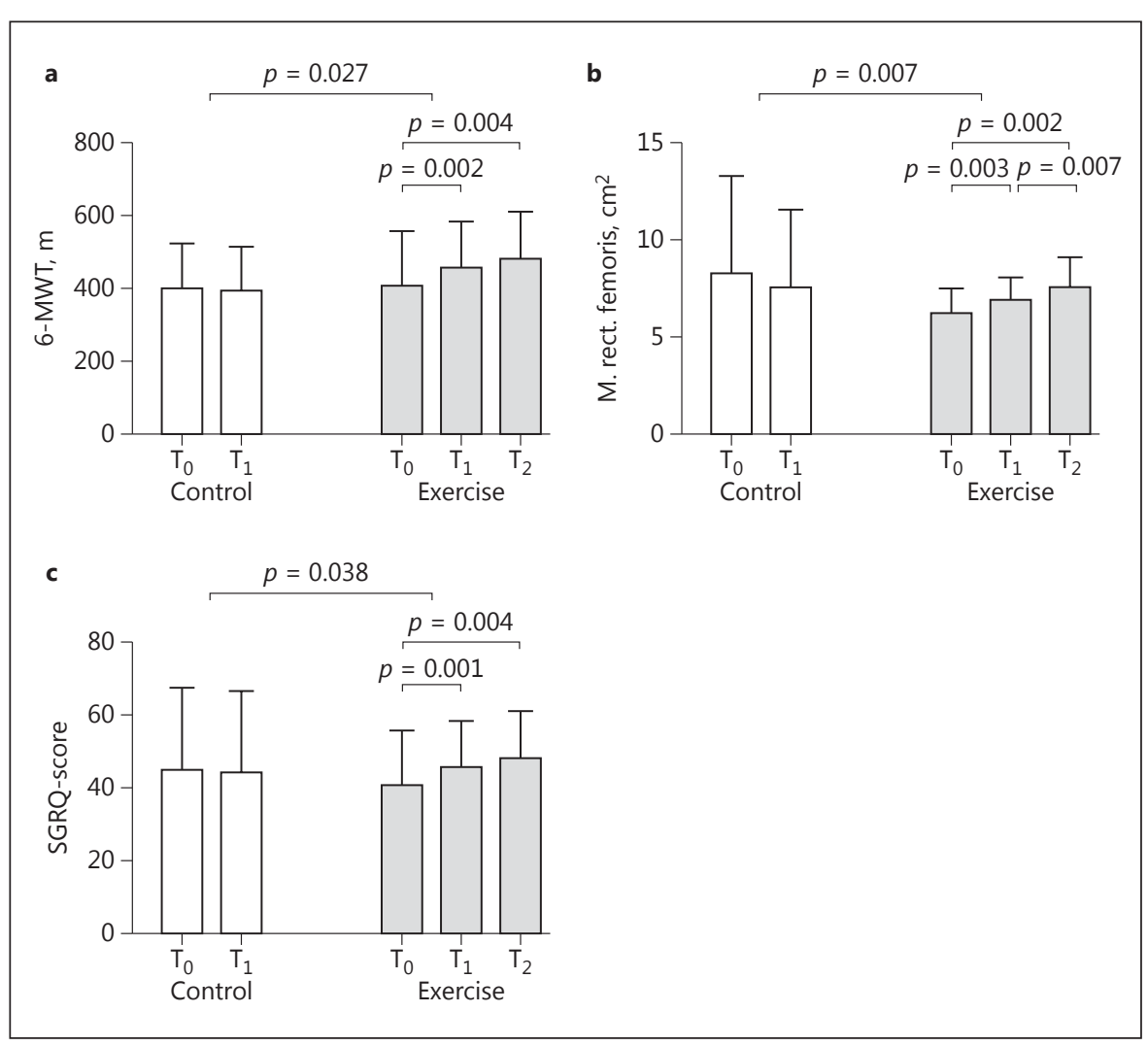

lated using SPSS 22 (IBM SPSS Statistics version 22.0; SPSS, Armonk, NY, USA) and Prism 5.03 (GraphPad Software, Inc., La Jolla, CA, USA). Two groups were compared using the MannWhitney $\mathrm{U}$ test for unpaired samples. Comparisons within a group were made with the Wilcoxon rank-sum test for paired samples. To compare measurements from several time points, Friedman's test for continuous and Fisher's exact test for categorical variables were used. All tests were 2 -sided $(p<0.05$ was considered to be significant). For independent samples, the Kruskal-Wallis test was applied.

\section{Results}

\section{Baseline Characteristics of the Patients}

A total of 49 of 119 screened patients (41.18\%) agreed to participate in the study; 31 were primarily assigned to the exercise group, and 18 to the control group. Twelve patients (35\% dropout rate) refused further participation, and thus 20 of the exercise group and 17 of the control group completed the first 3 months of the study. Subsequently, a further 6 patients dropped out during the second phase. In the control group, 1 patient withdrew informed consent (6\% dropout rate). Thus, 14 patients completed the 6-month training program (Fig. 1). The patients' baseline characteristics are given in Table 2.

\section{6-min Walk Test}

When compared to baseline $\left(\mathrm{T}_{0}=407.9 \pm 152.09 \mathrm{~m}\right)$, a significant improvement in 6-MWT distance was observed in the exercise group after the first $\left(\mathrm{T}_{1}=459.3 \pm\right.$ $126.6 \mathrm{~m} ; p=0.002)$ and the second training period $\left(\mathrm{T}_{2}=\right.$ $483.2 \pm 130.1 \mathrm{~m} ; p=0.004)$. No change was found in the control group $\left(\mathrm{T}_{0}=399.1 \pm 129.4 \mathrm{~m}, \mathrm{~T}_{1}=397.2 \pm 119.1\right.$ $\mathrm{m} ; p=0.979)$. In addition, a significant difference was found between the training and the control group ( $p=$ 0.027; Fig. 2a).

\section{Area of Musculus Rectus Femoris}

The exercise group demonstrated an increase in the cross-sectional area of the $\mathrm{m}$. rectus femoris $\left(\mathrm{T}_{0}=6.2 \pm\right.$ $1.2 \mathrm{~cm}^{2}, \mathrm{~T}_{1}=6.9 \pm 1.2 \mathrm{~cm}^{2}, p=0.003, \mathrm{~T}_{2}=7.5 \pm 1.6 \mathrm{~cm}^{2}$, $p=0.002)$, whereas the control group showed no change $\left(\mathrm{T}_{0}=8.2 \pm 4.9 \mathrm{~cm}^{2}, \mathrm{~T}_{1}=7.5 \pm 4.0 \mathrm{~cm}^{2}, p=0.249\right)$. Furthermore, a significant difference was observed at $\mathrm{T}_{2}$ between the control and the training group $(p=0.007$; Fig. 2b). 
Fig. 3. Percent change in maximum force

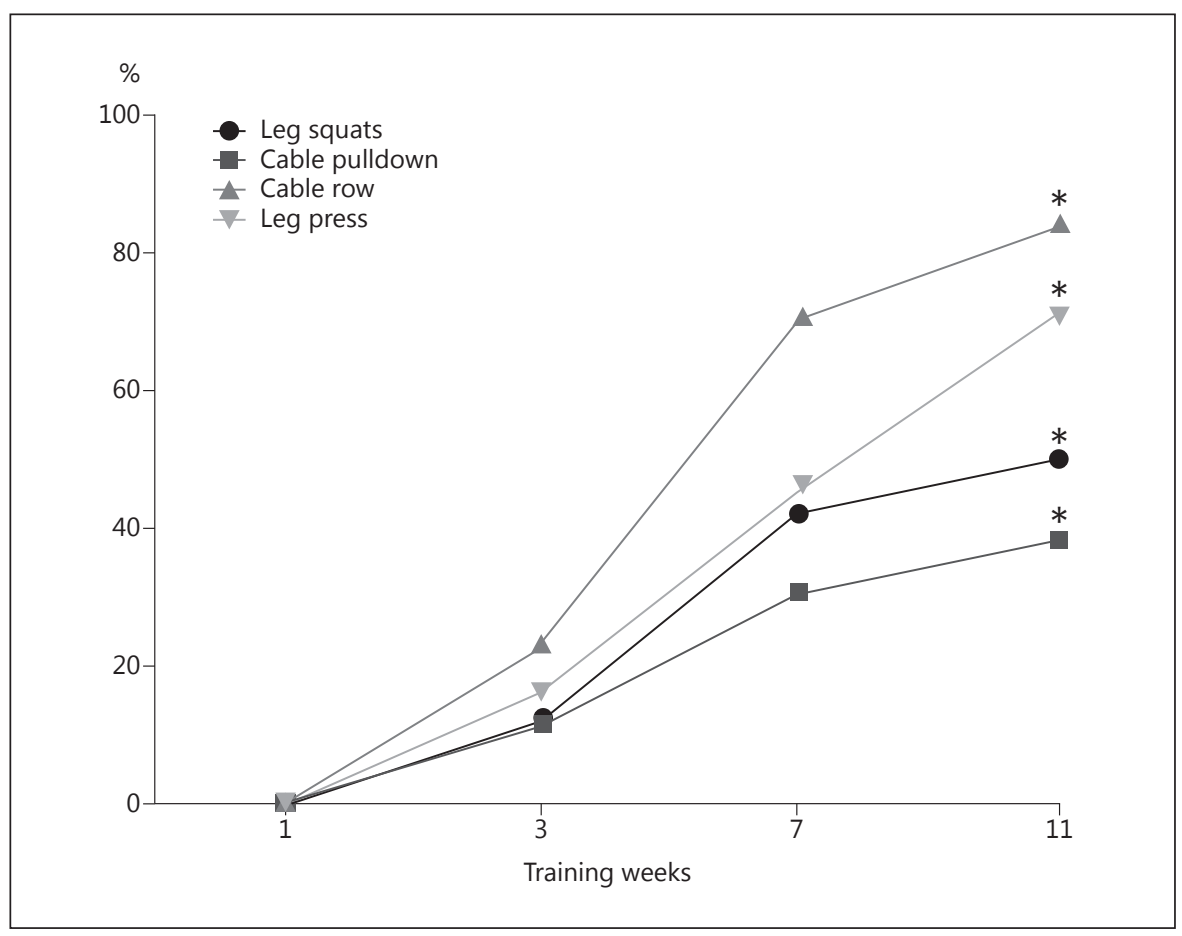
over 11 weeks. ${ }^{*} p<0.05$, Friedman's test.

\section{Quality of Life}

If compared to baseline $\left(\mathrm{T}_{0}\right)$, clinically relevant improvements in SGRQ total score were found within the exercise group after the first $\left(\mathrm{T}_{0}=43.3 \pm 18.0, \mathrm{~T}_{1}=36.0\right.$ $\pm 18.4 ; p=0.001)$ and the second period of training $\left(\mathrm{T}_{2}=\right.$ $34.7 \pm 18.0 ; p=0.004)$. In the control group, the SGRQ total score did not change $\left(\mathrm{T}_{0}=44.4 \pm 22.3, \mathrm{~T}_{1}=43.4 \pm\right.$ 22.2; $p=0.687$ ). The comparison of the groups at $\mathrm{T}_{2}$ showed a significant difference between the control and the training group ( $p=0.038$; Fig. $2 c)$.

\section{Intervention Setting within the First 3 Months}

The maximum force determination for training adjustment took place at baseline, as well as in the third, fifth, and eleventh training week. The lowest increase in maximum power was observed in cable pulldown (38\%) and in guided squats (50\%). However, leg press showed an increase in maximum force of $71 \%$, and cable row an increase of $84 \%$ compared to the baseline measurement. The percent changes in maximum force are shown in Figure 3.

\section{Serum Markers of Inflammation, Muscle-Derived}

Markers, and B-Type Natriuretic Peptide

In the control and the training group, serum levels of myostatin, irisin, resistin, and $\alpha$-Klotho did not change significantly within the training period (Table 3 ). It is noteworthy, however, that after the 6-month training program the exercise subgroup showed an inverse relationship between serum levels of resistin and those of $\alpha$-Klotho $(r=-0.608, p=0.021)$ (Fig. 4). No changes in the above measures were found in the controls.

B-type natriuretic peptide (BNP) was within the normal range in both groups during the study. It is noteworthy that a small, nonsignificant decrease was observed in the exercise group.

\section{Discussion}

The main finding of the present study is an improvement in 6-MWT distance of 52-76 m after high-intensity training. This represents a clinically important change and reflects an improvement in the patient's condition. 6-MWT distance is a potentially useful biomarker of COPD severity, which is influenced by muscle weakness, pulmonary vascular disease, or depression [19]. 6-MWT distance has also been a surrogate for predicting survival in observational studies [20]. The observed increase in 6-MWT distance is thought to be clinically relevant [21]. A few small studies have compared interval training with continuous training among patients with COPD, and the results are somewhat inconsistent. There have been sev- 


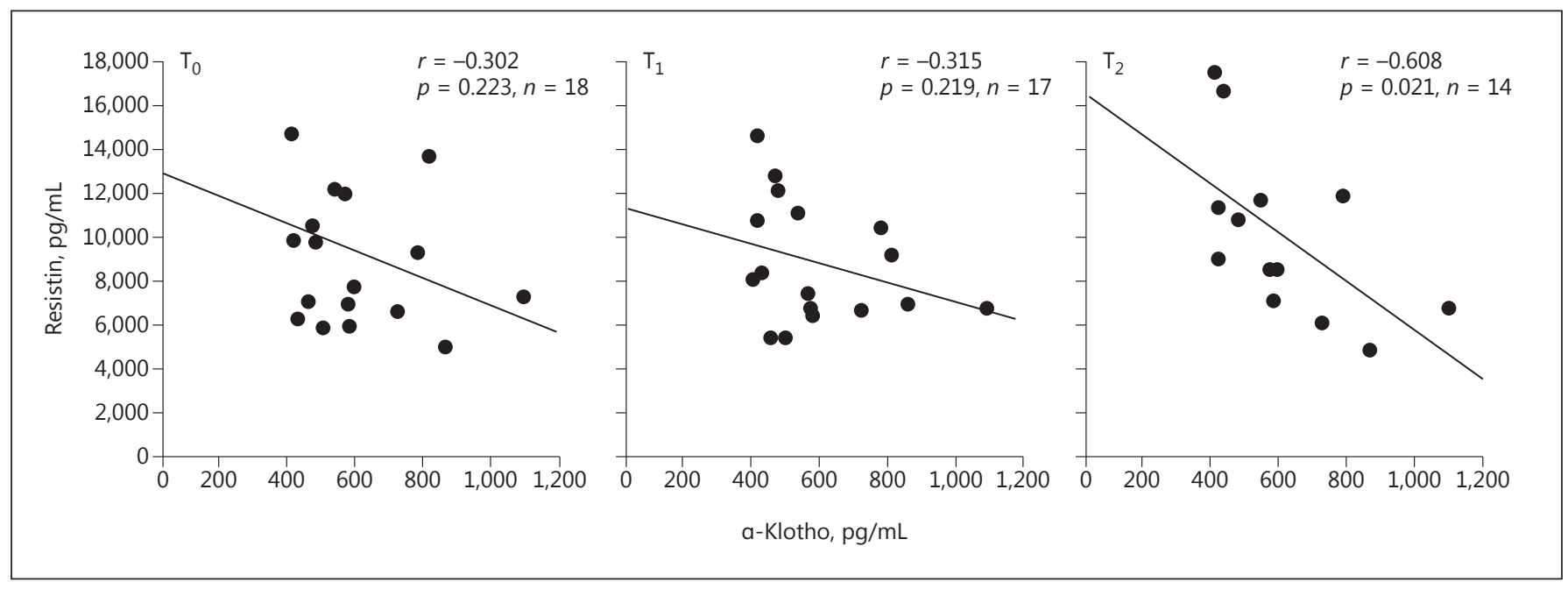

Fig. 4. Correlations between serum levels of resistin and $\alpha$-Klotho in a training group at the time points $T_{0}, T_{1}$, and $T_{2}$.

Table 3. Changes in serum markers within the study period

\begin{tabular}{|c|c|c|c|c|c|c|c|}
\hline \multirow[t]{2}{*}{ Marker } & \multicolumn{3}{|c|}{ Control group } & \multicolumn{3}{|c|}{ Exercise group } & \multirow[t]{2}{*}{$p$ value } \\
\hline & $\mathrm{T}_{0}$ & $\mathrm{~T}_{1}$ & $\mathrm{~T}_{2}$ & $\mathrm{~T}_{0}$ & $\mathrm{~T}_{1}$ & $\mathrm{~T}_{2}$ & \\
\hline Irisin, $\mathrm{pg} / \mathrm{mL}$ & $6.6 \pm 2$ & $6.6 \pm 1.6$ & $6.9 \pm 0.7$ & $7.8 \pm 1.7$ & $7.5 \pm 1.6$ & $7.7 \pm 1.6$ & ns \\
\hline a-Klotho, pg/mL & $655 \pm 120$ & $641 \pm 127$ & $602 \pm 158$ & $584 \pm 195$ & $590 \pm 180$ & $633 \pm 235$ & ns \\
\hline Myostatin, ng/mL & $3.2 \pm 1.6$ & $3.2 \pm 1.6$ & $2.6 \pm 1.2$ & $2.8 \pm 1.1$ & $2.7 \pm 1.2$ & $2.9 \pm 1.1$ & ns \\
\hline Resistin, ng/mL & $10 \pm 3.6$ & $9.6 \pm 3.2$ & $11 \pm 4.4$ & $9.7 \pm 3.9$ & $8.9 \pm 2.8$ & $10.2 \pm 3.7$ & ns \\
\hline
\end{tabular}

Data are presented as the mean $\pm \mathrm{SD}$.

eral randomized controlled trials comparing high- and low-intensity training among patients with COPD [22]. Some studies show that the magnitude of improvement in physiological responses is significantly greater in highintensity training than in low-intensity training $[23,24]$. On the other hand, in patients with severe COPD it can be difficult to sustain a high intensity with the continuous training modality, because lung hyperinflation (air trapping) may contribute to exercise intolerance [25]. The latest publication by Schaadt et al. [26] showed that in their small-sized study, the mortality risk increased among COPD patients after a biweekly high-intensity rehabilitation program. Furthermore, Greening et al. [27] demonstrated in a randomized trial that training of hospitalized COPD patients, including strength, endurance, and neuromuscular stimulation, resulted in short-term effects and higher mortality, although the study was not powered for mortality assessment. It is therefore suggested

Benefits of High-Intensity Exercise

Training to Patients with COPD that COPD rehabilitation programs should be designed carefully for every individual patient, and that additional studies are needed to determine the optimal duration, intensity, and frequency of rehabilitation programs.

Nevertheless, in our study $35 \%$ of the patients dropped out after 3 months and 30\% after a 6-month training program. The reasons for dropout were varied and not specifically related to the severity of COPD. For example, 1 patient was not able to leave his work, 1 patient received a new hip, and 2 patients were not able to complete all the measurements. Another 2 patients with severe COPD were ill for a longer period of time. We could observe that the dropout rate in the high-intensity COPD group was not above the $50 \%$ previously published for individualized and nonindividualized training groups [14, 28-30].

High-intensity rehabilitation exercise is known to increase the muscular aerobic metabolism that allows tolerating a higher magnitude of activity without limiting dys- 
pnea [31]. Previous studies have demonstrated that measurement of the $\mathrm{m}$. rectus femoris is a useful tool for monitoring changes in muscle strength [18]. Parallel to the increase in 6-MWT distance, the high-intensity exercise group showed an increase in cross-sectional area of the $\mathrm{m}$. rectus femoris after 3 months of $0.7 \mathrm{~cm}^{2}$, and after 6 months of $1.3 \mathrm{~cm}^{2}$. Our results confirm data from an earlier study showing an increase in cross-sectional area of the $\mathrm{m}$. rectus femoris of $0.57 \mathrm{~cm}^{2}$ after 8 weeks of high-intensity isokinetic knee extensor resistance training [28]. The greater effect in our cohort can at least in part be explained by the higher intensity and more individualized resistance training. Due to the limited number of patients in our study, further research is needed to draw any final conclusions.

We also demonstrated an improvement in SGRQ score of at least 8 points after high-intensity and low-frequency strength training in the exercise group, while no effect was detected in the control group. This finding is in line with other studies also showing improvements in quality of life after a period of exercise training [32, 33]. Regular meetings of patients play a key role in quality of life; training could promote group dynamics with regard to psychosocial support [32].

Finally, we assessed the levels of a few serum markers, such as myostatin (a myokine produced and released by myocytes that inhibits muscle cell growth and differentiation), irisin (a myokine linked to the positive benefits of exercise), resistin (a signal molecule associated with inflammation in COPD), and $\alpha$-Klotho (a novel $\beta$-glucuronidase associated with human aging). We did not observe any significant changes in the measured biomarkers; however, it is interesting to note that after 6 months of high-intensity training, we found an inverse correlation between serum levels of resistin and those of $\alpha$-Klotho. Klotho is an antiaging protein having anti-inflammatory functions $[34,35]$. Klotho expression has been found to be reduced in the lungs of smokers and patients with COPD. Many clinical studies have suggested that soluble Klotho exerts strong cardioprotective effects, since higher Klotho levels were related to a lower incidence of mortality and cardiovascular disease [36]. In contrast, resistin is linked to inflammation and senescence. For example, the results from a cross-sectional study which included 412 subjects of different ages revealed that in old subjects resistin is inversely associated with muscle strength [37]. In older adults, higher resistin levels have also been found to be associated with cardiovascular events [38]. An experimental study suggested that resistin may induce hepatocyte senescence [39]. Hence, the inverse relationship between serum levels of Klotho and resistin levels after a 6-month high-intensity training further supports the clinical improvements among COPD patients discussed above.

A variety of cardiopulmonary interactions have been described in COPD [40]. Besides common shared risk factors, pathophysiological mechanisms linking heart size, morphology, and function to COPD should be taken into account. BNP is a surrogate marker for increased ventricular distending forces and wall stress $[41,42]$. BNP levels were not increased in the present study, which argues against patent heart failure and increased wall stress [43]. However, it is noteworthy that a nonsignificant decrease within the normal range was observed in the training group. This is in accordance with previous findings showing physiological cardiac hypertrophy caused by exercise training in COPD [44].

In sum, our results show that high-intensity training twice a week during 3-6 months is feasible for many patients at different stages of COPD and results in a significant improvement of exercise capacity, muscle mass, and quality of life if compared to untrained patients. The baseline characteristics of those in the exercise and control groups who completed the study indicate that overall the control group was less health conscious, including more cases with obesity, smoking habits, and comorbidities. This supports the notion that high-intensity training twice a week during 3-6 months is feasible only for very highly motivated COPD patients. We assessed depression and anxiety via standardized questionnaires. The patients did not show any values within the range which defines clinically relevant anxiety and depression. However, we detected a trend toward reduced values after 3 and 6 months in the exercise group. This could indicate an elevation of mood after exercising.

It is a limitation of this study that only a small number of patients were enrolled. This might reflect a well-known characteristic of COPD patients, namely, that they are hard to motivate to perform exercises, particularly with a training concept with increased loads. Based on our results, we conclude that it is feasible for COPD patients to undergo a high-intensity training 2 times a week. We cannot exclude a potential bias that led to the overproportionate inclusion of highly motivated patients.

\section{Conclusion}

Different training programs have been shown to exhibit positive effects on COPD patients who were able to complete their exercise training programs. Nevertheless,
308

Respiration 2017;93:301-310

DOI: $10.1159 / 000464139$
Boeselt et al. 
it is still unclear which exercise modalities are the most effective. High-intensity training twice a week during 3-6 months is feasible for patients with mild COPD and results in a significant improvement of exercise capacity, muscle mass, and quality of life. It is important to point out that $50 \%$ of the study population of the high-intensity training arm who completed the nonrandomized study were COPD patients at GOLD stage I. Therefore, a second conclusion is that patients with mild-to-moderate COPD who are able to complete the training program are assumed to benefit from it.

\section{Statement of Ethics}

Every patient gave informed written consent to participate in the study. The study was approved by the Ethics Committee of Philipps-Universität Marburg (Ethics Committee AZ 7/13, Marburg, Germany) and registered (DRKS00006842).

\section{Financial Disclosure and Conflicts of Interest}

The authors declare that they have no competing interests.

\section{Author Contributions}

T.B. contributed to the study hypothesis and study design as well as to writing of the manuscript and shared in scientific discussions. C.N. contributed to the study hypothesis and study design and performed the statistical analysis of the study and data collection. M.S. contributed to writing of the manuscript and shared in scientific discussions. L.L. contributed to writing and reviewing of the manuscript and shared in scientific discussions. K.K. contributed to the organization of the study and data collection and shared in scientific discussions. J.K. supervised the training sessions and performed the data collection. S.A., M.V., B.B., T.G., C.F.V., K.K., S.J., and P.A. reviewed the manuscript and shared in scientific discussions. A.R.K. contributed to the study design, reviewed the manuscript, and shared in scientific discussions.

\section{References}

1 Lopez AD, Shibuya K, Rao C, Mathers CD, Hansell AL, Held LS, et al: Chronic obstructive pulmonary disease: current burden and future projections. Eur Respir J 2006;27:397412.

2 Caspersen CJ, Powell KE, Christenson GM: Physical activity, exercise, and physical fitness: definitions and distinctions for healthrelated research. Public Health Rep 1985;100: $126-131$.

3 Cooper CB: The connection between chronic obstructive pulmonary disease symptoms and hyperinflation and its impact on exercise and function. Am J Med 2006;119(suppl 1):21-31.

4 Wagner PD: Skeletal muscles in chronic obstructive pulmonary disease: deconditioning, or myopathy? Respirology 2006;11:681-686.

5 Lacasse Y, Brosseau L, Milne S, Martin S, Wong E, Guyatt GH, et al: Pulmonary rehabilitation for chronic obstructive pulmonary disease. Cochrane Database Syst Rev 2002;3: CD003793.

6 Spruit MA, Augustin IM, Vanfleteren LE, Janssen DJ, Gaffron S, Pennings HJ, et al: Differential response to pulmonary rehabilitation in COPD: multidimensional profiling. Eur Respir J 2015;46:1625-1635.

7 McCarthy B, Casey D, Devane D, Murphy K, Murphy E, Lacasse Y: Pulmonary rehabilitation for chronic obstructive pulmonary disease. Cochrane Database Syst Rev 2015;2: CD003793.

8 Vincent E, Sewell L, Wagg K, Deacon S, Williams J, Singh S: Measuring a change in selfefficacy following pulmonary rehabilitation: an evaluation of the PRAISE tool. Chest 2011; 140:1534-1539.
9 Puente-Maestu L, Lázaro A, Tejedor A, Camaño S, Fuentes M, Cuervo M, et al: Effects of exercise on mitochondrial DNA content in skeletal muscle of patients with COPD. Tho$\operatorname{rax} 2011 ; 66: 121-127$.

10 Remels AH, Gosker HR, Schrauwen P, Hommelberg PP, Sliwinski P, Polkey M, et al: TNF- $\alpha$ impairs regulation of muscle oxidative phenotype: implications for cachexia? FASEB J 2010;24:5052-5062.

11 Tang K, Wagner PD, Breen EC: TNF- $\alpha-$ mediated reduction in PGC-1a may impair skeletal muscle function after cigarette smoke exposure. J Cell Physiol 2010;222:320-327.

12 Griffiths TL, Phillips CJ, Davies S, Burr ML, Campbell IA: Cost effectiveness of an outpatient multidisciplinary pulmonary rehabilitation programme. Thorax 2001;56:779-784.

13 Spruit MA, Singh SJ, Garvey C, ZuWallack R, Nici L, Rochester C, et al: An official American Thoracic Society/European Respiratory Society statement: key concepts and advances in pulmonary rehabilitation. Am J Respir Crit Care Med 2013;188:e13-e64.

14 Ries AL, Bauldoff GS, Carlin BW, Casaburi R, Emery CF, Mahler DA, et al: Pulmonary rehabilitation: joint ACCP/AACVPR evidencebased clinical practice guidelines. Chest 2007; 131(suppl):4S-42S.

15 Radlinger L, Bachmann W, Homburg J, Leuenberger U, Thaddey G: Rehabilitatives Krafttraining. Stuttgart/New York, Thieme, 1998.

16 Jenkins SC: 6-minute walk test in patients with COPD: clinical applications in pulmonary rehabilitation. Physiotherapy 2007;93: 175-182.
17 Jones PW, Quirk FH, Baveystock CM, Littlejohns P: A self-complete measure of health status for chronic airflow limitation. The St. George's Respiratory Questionnaire. Am Rev Respir Dis 1992;145:1321-1327.

18 Seymour JM, Ward K, Sidhu PS, Puthucheary $\mathrm{Z}$, Steier J, Jolley CJ, et al: Ultrasound measurement of rectus femoris cross-sectional area and the relationship with quadriceps strength in COPD. Thorax 2009;64:418-423.

19 Spruit MA, Polkey MI, Celli B, Edwards LD, Watkins ML, Pinto-Plata V, et al: Predicting outcomes from 6-minute walk distance in chronic obstructive pulmonary disease. J Am Med Dir Assoc 2012;13:291-297.

20 Pinto-Plata VM, Cote C, Cabral H, Taylor J, Celli BR: The 6-min walk distance: change over time and value as a predictor of survival in severe COPD. Eur Respir J 2004;23:28-33.

21 Hui KP, Hewitt AB: A simple pulmonary rehabilitation program improves health outcomes and reduces hospital utilization in patients with COPD. Chest 2003;124:94-97.

22 Tanaka T, Arizono S, Hanada M, Senjyu H: High-intensity lower limb endurance training in chronic respiratory disease. Nagasaki Univ Acad Output Site 2015;27:1-11.

23 Punzal PA, Ries AL, Kaplan RM, Prewitt LM: Maximum intensity exercise training in patients with chronic obstructive pulmonary disease. Chest 1991;100:618-623.

24 Gimenez M, Servera E, Vergara P, Bach JR, Polu JM: Endurance training in patients with chronic obstructive pulmonary disease: a comparison of high versus moderate intensity. Arch Phys Med Rehabil 2000;81:102-109.
Benefits of High-Intensity Exercise

Training to Patients with COPD
Respiration 2017;93:301-310 DOI: $10.1159 / 000464139$ 
25 O'Donnell DE, Revill SM, Webb KA: Dynamic hyperinflation and exercise intolerance in chronic obstructive pulmonary disease. Am J Respir Crit Care Med 2001;164:770-777.

26 Schaadt L, Christensen R, Kristensen LE, Henriksen M: Increased mortality in patients with severe COPD associated with high-intensity exercise: a preliminary cohort study. Int J Chron Obstruct Pulmon Dis 2016;11: 2329-2334.

27 Greening NJ, Williams JE, Hussain SF, Harvey-Dunstan TC, Bankart MJ, Chaplin EJ, et al: An early rehabilitation intervention to enhance recovery during hospital admission for an exacerbation of chronic respiratory disease: randomised controlled trial. BMJ 2014; 349:g4315.

28 Menon MK, Houchen L, Harrison S, Singh SJ, Morgan MD, Steiner MC: Ultrasound assessment of lower limb muscle mass in response to resistance training in COPD. Respir Res 2012;13:119.

29 Divo M, Cote C, de Torres JP, Casanova C, Marin JM, Pinto-Plata V, et al: Comorbidities and risk of mortality in patients with chronic obstructive pulmonary disease. Am J Respir Crit Care Med 2012;186:155-161.

30 Effing T, Zielhuis G, Kerstjens H, van der Valk P, van der Palen J: Community based physiotherapeutic exercise in COPD selfmanagement: a randomised controlled trial. Respir Med 2011;105:418-426.
31 Gibala MJ, Little JP, Macdonald MJ, Hawley JA: Physiological adaptations to low-volume, high-intensity interval training in health and disease. J Physiol 2012;590:1077-1084.

32 Göhl O, Linz H, Schönleben T, Otte B, Weineck J, Worth $\mathrm{H}$ : Benefits of a multimodular outpatient training program for patients with COPD (in German). Pneumologie 2006;60: 529-536.

33 Zambom-Ferraresi F, Cebollero P, Gorostiaga EM, Hernández M, Hueto J, Cascante J, et al: Effects of combined resistance and endurance training versus resistance training alone on strength, exercise capacity, and quality of life in patients with COPD. J Cardiopulm Rehabil Prev 2015;35:446-453.

34 Avin KG, Coen PM, Huang W, Stolz DB, Sowa GA, Dubé JJ, et al: Skeletal muscle as a regulator of the longevity protein, Klotho. Front Physiol 2014;5:189.

35 Matsubara T, Miyaki A, Akazawa N, Choi Y, Ra SG, Tanahashi K, et al: Aerobic exercise training increases plasma Klotho levels and reduces arterial stiffness in postmenopausal women. Am J Physiol Heart Circ Physiol 2014;306:H348-H355.

36 Kuro-o M: Klotho as a regulator of oxidative stress and senescence. Biol Chem 2008;389: 233-241.

37 Bucci L, Yani SL, Fabbri C, Bijlsma AY, Maier $A B$, Meskers CG, et al: Circulating levels of adipokines and IGF-1 are associated with skeletal muscle strength of young and old healthy subjects. Biogerontology 2013;14: 261-272.
38 Gencer B, Auer R, de Rekeneire N, Butler J, Kalogeropoulos A, Bauer DC, et al: Association between resistin levels and cardiovascular disease events in older adults: the Health, Aging and Body Composition study. Atherosclerosis 2016;245:181-186.

39 Yu A, Zheng Y, Zhang R, Huang J, Zhu Z, Zhou R, et al: Resistin impairs SIRT1 function and induces senescence-associated phenotype in hepatocytes. Mol Cell Endocrinol 2013;377:23-32.

40 Alter P, van de Sand K, Nell C, Figiel JH, Greulich T, Vogelmeier CF, et al: Airflow limitation in COPD is associated with increased left ventricular wall stress in coincident heart failure. Respir Med 2015;109:1131-1137.

41 Alter P, Rupp H, Rominger MB, Vollrath A, Czerny F, Figiel JH, et al: B-type natriuretic peptide and wall stress in dilated human heart. Mol Cell Biochem 2008;314:179-191.

42 Alter P, Rupp H, Rominger MB, Czerny F, Vollrath A, Klose KJ, et al: A new method to assess ventricular wall stress in patients with heart failure and its relation to heart rate variability. Int J Cardiol 2010;139:301-303.

43 Alter P, Koczulla AR, Nell C, Figiel JH, Vogelmeier CF, Rominger MB: Wall stress determines systolic and diastolic function - characteristics of heart failure. Int J Cardiol 2016; 202:685-693.

44 Alter P, Luetteken L, Nell C, Haid D, Kehr K, Greulich T, et al: Exercise training leads to physiological left ventricular hypertrophy in COPD. Int J Cardiol 2014;174:156-157. 